\title{
Intramembrane protease RasP boosts protein production in Bacillus
}

\author{
Jolanda Neef ${ }^{1 \dagger}$, Cristina Bongiorni ${ }^{2 \dagger}$, Vivianne J. Goosens ${ }^{1,3}$, Brian Schmidt ${ }^{2}$ and Jan Maarten van Dijl ${ }^{1 *}$
}

\begin{abstract}
Background: The microbial cell factory Bacillus subtilis is a popular industrial platform for high-level production of secreted technical enzymes. Nonetheless, the effective secretion of particular heterologous enzymes remains challenging. Over the past decades various studies have tackled this problem, and major improvements were achieved by optimizing signal peptides or removing proteases involved in product degradation. On the other hand, serious bottlenecks in the protein export process per se remained enigmatic, especially for protein secretion at commercially significant levels by cells grown to high density. The aim of our present study was to assess the relevance of the intramembrane protease RasP for high-level protein production in B. subtilis.

Results: Deletion of the ras $P$ gene resulted in reduced precursor processing and extracellular levels of the overproduced a-amylases AmyE from B. subtilis and AmyL from Bacillus licheniformis. Further, secretion of the overproduced serine protease BPN'from Bacillus amyloliquefaciens was severely impaired in the absence of RasP. Importantly, overexpression of rasP resulted in threefold increased production of a serine protease from Bacillus clausii, and 2.5- to 10-fold increased production of an AmyAc a-amylase from Paenibacillus curdlanolyticus, depending on the culture conditions. Of note, growth defects due to overproduction of the two latter enzymes were suppressed by rasP-overexpression.

Conclusion: Here we show that an intramembrane protease, RasP, sets a limit to high-level production of two secreted heterologous enzymes that are difficult to produce in the B. subtilis cell factory. This finding was unexpected and suggests that proteolytic membrane sanitation is key to effective enzyme production in Bacillus.
\end{abstract}

Keywords: Bacillus, RasP, Site-2 protease, Secretion, Amylase, Protease

\section{Background}

Secretory protein production is of critical importance in biotechnology, because this generally delivers high amounts of correctly folded proteins for which downstream processing from the fermentation broth is relatively easy. The Gram-positive bacterium Bacillus subtilis and related bacilli are amongst the best protein producers known today and, therefore, frequently used to produce commercially relevant enzymes. In particular, these organisms are suitable for large-scale high-density fermentation, leading to product yields in the $25 \mathrm{~g} / \mathrm{l}$ range

\footnotetext{
${ }^{*}$ Correspondence: j.m.van.dij|01@umcg.nl

†'olanda Neef and Cristina Bongiorni contributed equally to this work

${ }^{1}$ Department of Medical Microbiology, University of Groningen,

University Medical Center Groningen, Hanzeplein 1, P.O. Box 30001, 9700

RB Groningen, The Netherlands

Full list of author information is available at the end of the article
}

[1]. Thus, they have a long history in the production of, for example, amylases [2,3] and proteases [2, 4] used in the food, textile and pharmaceutical industries [5]. Another advantage of $B$. subtilis and its close relatives is that they lack toxic by-products, such as endotoxin, which makes them suitable for the Qualified Presumption of Safety (QPS) status of the European Food Safety Authority. Accordingly, many Bacillus products have obtained the Generally Recognized As Safe (GRAS) status from the US Food and Drug Administration $[6,7]$.

Much effort has been made to optimize protein secretion in B. subtilis. Major improvements were achieved by optimizing signal peptides $[8,9]$ or removing proteases involved in product degradation [10]. For example, the deletion of multiple genes for extracellular proteolytic enzymes allowed efficient production not only of technical enzymes, such as a thermostable $\beta$-1,3-1,4-glucanase 
from Clostridium thermocellum [11], but also of pharmaceutical proteins, such as single-chain antibodies [12] or human interleukin-3 [13]. Further improvements in protein secretion were achieved at lab-scale by overexpression of the signal peptidase SipS [14], the peptidyl-prolyl cis/trans isomerase PrsA [15], or the staphylococcal thioldisulphide oxidoreductase DsbA [16]. Nonetheless, serious bottlenecks in the protein export process per se have remained enigmatic, especially for protein secretion at commercially significant levels by cells grown to high density [17].

Notably, it was previously shown that deleting the gene for the intramembrane protease RasP of B. subtilis led to elevated levels of the membrane proteins FtsL [18], $\mathrm{HtrA}$ and HtrB, but compromised the production of various other membrane proteins [19] and processing of the $\alpha$-amylase AmyQ of Bacillus amyloliquefaciens $[20,21]$. This focused our attention on a possible role of RasP in secretory protein production, especially because the biogenesis of many membrane proteins relies on the general secretory pathway [22]. RasP belongs to the family of site-2 proteases (S2P), more specifically the zink-metallo proteases, which cleave their substrates within the plane of the cytoplasmic membrane [23]. These proteases are conserved in all domains of life where they have roles in regulated intramembrane proteolysis. For instance, the Escherichia coli S2P named RseP was shown to cleave signal peptides upon their signal peptidase-mediated liberation from secretory precursor proteins $[24,25]$. B. subtilis RasP was shown to cleave the anti-sigma factor RsiW under conditions of oxidative- or temperature stress, causing induction of the so-called $\sigma^{\mathrm{W}}$ regulon, which is believed to support cell envelope integrity and to mitigate effects of extracellular stress [20, 21, 26, 27]. Therefore, the present study was aimed at determining whether RasP could be a bottleneck for protein production in $B$. subtilis. Indeed, our results show that RasP overexpression can boost protein production in this important cell factory.

\section{Methods}

\section{Bacterial strains and growth conditions}

The bacterial strains used in this study are listed in Table 1. B. subtilis strains were grown at $37^{\circ} \mathrm{C}, 280 \mathrm{rpm}$ in Lysogeny Broth (LB; Oxoid Limited), MBU medium or 5SM12 medium. The MBU medium is similar to the MBD medium as described by Vogtentanz et al. [28], but lacks soytone and instead of $7.5 \%$ glucose it contains $2.1 \%$ glucose and $3.5 \%$ maltodextrin DE13-17. The 5SM12 medium consists of $75 \mathrm{mM} \mathrm{K}_{2} \mathrm{HPO}_{4}, 25 \mathrm{mM} \mathrm{NaH}_{2} \mathrm{PO}_{4}$, $12 \%$ maltodextrin, 5\% Difco Bacto Soytone, $2 \mathrm{mM}$ sodium citrate, $0.5 \mathrm{mM} \mathrm{MgSO}_{4}, 0.2 \mathrm{mM} \mathrm{MnCl} 2,0.03 \mathrm{mM}$ calcium chloride, and $0.0053 \%$ ferric ammonium citrate.
Growth media were supplemented with neomycin $15 \mu \mathrm{g} /$ $\mathrm{ml}$ or phleomycin $4 \mu \mathrm{g} / \mathrm{ml}$ to select for particular gene deletions. Chloramphenicol was added to 5 or $25 \mu \mathrm{g} / \mathrm{ml}$ for, respectively, the selection of chromosomally integrated amylase or protease expression cassettes and their amplification. In pulse-chase labeling experiments with cells grown on MBU medium, $2.5 \mu \mathrm{g} / \mathrm{ml}$ chloramphenicol was used.

\section{Construction of strains and plasmids}

Ex Taq polymerase, dNTPs and buffers used for the construction of mutant strains were purchased from Takara Bio Inc. Phusion High Fidelity DNA polymerase (New England Biolabs) was used for the construction of plasmids. Primers were obtained from Eurogentec. Construction of deletion mutants in a B. subtilis $\Delta u p p:: n e o^{R}$ strain was performed using the modified mutation delivery method described by Fabret et al. [29]. To delete a particular gene of interest (i.e. rasP or tepA), its $5^{\prime}$ and $3^{\prime}$ flanking regions were amplified using primer pairs designated P1/P2 and P3/P4 (Table 2). The amplified fragments were fused to a cassette containing a phleomycin resistance marker, the upp gene and the $c I$ gene [29]. The resulting fusion product was used to transform $B$. subtilis $\Delta$ upp::neo ${ }^{R}$, where competence was induced with $0.3 \%$ xylose due to the presence of a xylose-inducible $\operatorname{comK}$ gene. This resulted in phleomycin resistant and neomycin sensitive strains lacking the target gene. PCRs using primer combinations $\mathrm{P} 0 / \mathrm{P} 4$ and $\mathrm{P} 0 / \mathrm{CI} 2$.rev (Table 2) were performed to verify the correct deletion. To achieve overproduction and secretion of AmyE [30], AmyL [31] or $\mathrm{BPN}^{\prime}-\mathrm{Y} 217 \mathrm{~L}$ (in short BPN') [32,33], the promoter of $\operatorname{aprE~(600~bp~upstream~of~the~GTG~start~codon)~[34]~and~}$ the signal sequence of aprE were fused to the 7-codon pro-sequence of $a m y E$, the $a m y L$ gene lacking its signal sequence, or the eighth codon of the $\mathrm{BPN}^{\prime}$ signal sequence, respectively. For AmyE, the C-terminal starchbinding module was removed by the introduction of a stop codon after the codon for residue 425 in $a m y E$ and the complete gene expression cassette was produced synthetically (GeneOracle, Santa Clara, CA). Transcription of $a m y E$ or $b p n^{\prime}$ was terminated using the native BPN' terminator, and the native terminator in case of $a m y L$. To accomplish the expression and secretion of Properase ${ }^{\circledR}$ (i.e. the subtilisin variant of Bacillus clausii) or AmyAc [i.e. an engineered $\alpha$-amylase from Paenibacillus curdlanolyticus that belongs to the AmyAc family (NCBI reference sequence: WP_040711139)], the respective genes were ordered synthetically (GeneArt, Thermofisher Scientific) and fused to the promoter and signal sequence of $a p r E$ as described above. For transcription termination, the native $\mathrm{BPN}^{\prime}$ terminator was used. Genes encoding the five afore-mentioned secretory proteins were integrated 
Table 1 Bacterial strains used in this study

\begin{tabular}{|c|c|c|}
\hline & Relevant genotypes and phenotypes & Source or reference \\
\hline \multicolumn{3}{|l|}{ B. subtilis strain } \\
\hline$\triangle u p p$ & degUHy32, amyE::xyIRPxy|AcomK-ermC, $\triangle$ upp::neoR, Neo ${ }^{R}$ & This study \\
\hline AmyL & degUHy32, amyE::xyIRPxy|AcomK-ermC, aprE::PaprE-amyL catRTbpn'; Em ; Cm ${ }^{R}$ & This study \\
\hline AmyE & degUHy32, amyE::xyIRPxy|AcomK-ermC, aprE::PaprE-amyE catRTbpn'; Em $; \mathrm{Cm}^{R}$ & This study \\
\hline $\mathrm{BPN}^{\prime}$ & degUHy32, amyE::xyIRPxy|AcomK-ermC, aprE::PaprE-bpn' catRTbpn'; Em $; \mathrm{Cm}^{\mathrm{R}}$ & This study \\
\hline$\triangle \mathrm{ras} P$ & degUHy32, amyE::xyIRPxylAcomK-ermC, $\Delta$ upp::neoR, $\Delta$ rasP::upp-phleoR-cl Em ; Phleo ${ }^{R} ; \mathrm{Neo}^{S}$ & This study \\
\hline AmyL $\triangle$ ras $P$ & $\begin{array}{l}\text { degUHy32, amyE::xylRPxylAcomK-ermC, aprE::PaprE-amyL catR, } \triangle \text { upp::neoR, } \triangle \text { rasP:::upp-phleoR-cl catR; Em; } \\
\text { Phleo ; } \text { Neo }^{S} \mathrm{Cm}^{R}\end{array}$ & This study \\
\hline AmyE $\triangle$ ras $P$ & 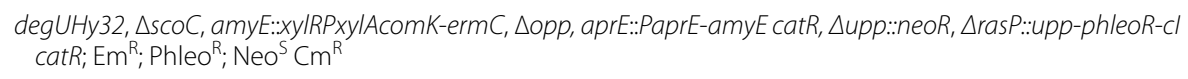 & This study \\
\hline BPN' $\triangle$ ras $P$ & 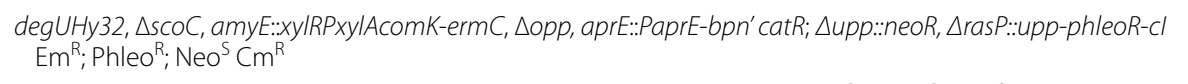 & This study \\
\hline$\triangle t e p A$ & 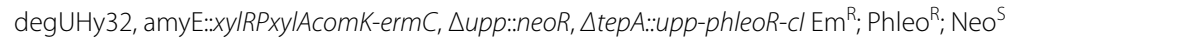 & This study \\
\hline AmyL $\triangle t e p A$ & $\begin{array}{l}\text { degUHy32, amyE::xylRPxylAcomK-ermC, aprE::PaprE-amyL catR, } \triangle \text { upp::neoR, } \triangle \text { tepA::upp-phleoR-cl catR; Em } \\
\text { Phleo } ;\end{array}$ & This study \\
\hline AmyE $\triangle$ tepA & $\begin{array}{l}\text { degUHy32, amyE::xylRPxylAcomK-ermC, aprE::PaprE-amyE catR, } \triangle \text { upp::neoR, } \Delta \text { tepA::upp-phleoR-cl catR; Em } \\
\text { Phleo } ;\end{array}$ & This study \\
\hline BPN' $\triangle$ tepA & $\begin{array}{l}\text { degUHy32, amyE::xylRPxylAcomK-ermC, aprE::PaprE-bpn' catR; } \triangle \text { upp::neoR, } \Delta \text { tepA::upp-phleoR-cl Em'; Phleo ; } \\
\text { Neo } \mathrm{Cm}^{\mathrm{R}}\end{array}$ & This study \\
\hline Properase & degUHy32, amyE::xyIRPxy|AcomK-ermC, aprE::PaprE-properase catRTbpn'; EmR $; \mathrm{Cm}^{R}$ & This study \\
\hline $\begin{array}{l}\text { Properase } \\
\text { RasP }\end{array}$ & degUHy32, amyE::xyIRPxyIAcomK-ermC, aprE::PaprE-properase catRTbpn', spollIAH::PspoVG-rasP; Em ; Cm & This study \\
\hline AmyAc & degUHy32, amyE::xyIRPxyIAcomK-ermC, aprE::PaprE-amyAccatRTbpn'; Em ; Cm ${ }^{R}$ & This study \\
\hline AmyAc RasP & degUHy32, amyE::xyIRPxyIAcomK-ermC, aprE::PaprE-amyAccatRTbpn', spollIAH::PspoVG-rasP; EmR Cm $^{R}$ & This study \\
\hline \multicolumn{3}{|l|}{ Plasmids } \\
\hline pHT315- $\mathrm{P}_{\text {spac }}$ & Multicopy shuttle vector replicating in E. coli and B. subtilis contains IPTG-inducible $P_{\text {spaci }} A_{m p^{R}}, E^{R}$ & Genencor/dupont [44] \\
\hline pHTK315 & pHT315- $\mathrm{P}_{\text {spac }}$ derivative, $\mathrm{Em}^{\mathrm{R}}$ is replaced by $\mathrm{Km}^{\mathrm{R}} ; \mathrm{Amp}^{R}, \mathrm{Km}^{R}$ & This study \\
\hline pHT315K::rasP & 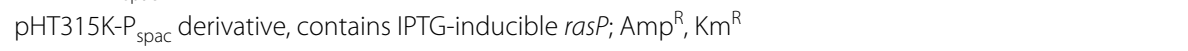 & This study \\
\hline
\end{tabular}

Tbpn' terminator structure of B. amyloliquefaciens $b p n^{\prime} ; E^{R}$ erythromycin resistant; $P h l e o^{R}$ phleomycin resistant; $N_{e o}{ }^{R}$ neomycin resistant; Neo $^{S}$ neomycin sensitive; $\mathrm{Cm}^{R}$ chloramphenicol resistant; $A m p^{R}$ ampicillin resistant; $K \mathrm{Km}^{R}$ kanamycin resistant

into the aprE locus by single cross-over recombination using a vector based on plasmid pJH101 [35]. Lastly, gene amplification was achieved by growing transformants at increasing chloramphenicol concentrations up to $25 \mu \mathrm{g} /$ $\mathrm{ml}$.

To complement the $\Delta$ rasP mutation, plasmid pHTK315, a derivative of pHT315- $\mathrm{P}_{\text {spac }}$ [36] containing the kan gene for kanamycin resistance was constructed using the CPEC strategy described by Quan et al. [37]. Plasmid pHT315- $\mathrm{P}_{\text {spac }}$ was amplified by PCR using the primers pHT315CPEC.fw and pHT315CPEC.rev. In parallel, the kan gene was amplified from the vector pGDL48 [38], using the primers kanaCPEC.fw and kanaCPEC. rev both containing approximately 30 bp overlap with the pHT315- $\mathrm{P}_{\text {spac }}$ vector. The two resulting PCR fragments were fused and amplified by PCR, and the resulting amplicon was used to transform competent cells of $E$. coli strain TG1. The plasmid thus obtained was named pHTK315. Next, plasmid pHTK315-rasP was constructed following the same strategy. For amplification of pHTK315, the primer combination pHT315rasP.fw/ pHT315rasP.rev was used, and rasP was amplified using the primer combinations rasP.fw/rasP.rev. Both fragments were fused by PCR based on the 30 bp overlaps. The resulting amplicon was used to transform competent cells of $E$. coli TG1, and the plasmid thus obtained was named pHTK315-rasP. The correctness of pHTK315 and pHTK315-rasP was verified by sequencing and, subsequently, these plasmids were introduced into B. subtilis using xylose-induced competence, as described above. After the transformation, mutant strains containing amplified $a m y E$, $a m y L$ or $b p n^{\prime}$ expression cassettes were selected by repeated transfers to fresh LB plates containing $25 \mu \mathrm{g} / \mathrm{ml}$ chloramphenicol.

\section{Analysis of secreted protein production by LDS-PAGE}

Cultures were inoculated from LB plates with $25 \mu \mathrm{g} / \mathrm{ml}$ chloramphenicol and grown for approximately $8 \mathrm{~h}$ in LB broth with $25 \mu \mathrm{g} / \mathrm{ml}$ chloramphenicol. These cultures were diluted 1000-fold in MBU medium with $2.5 \mu \mathrm{g} / \mathrm{ml}$ 
Table 2 Primers used in this study

\begin{tabular}{|c|c|}
\hline Primer name & $5^{\prime} \rightarrow 3^{\prime}$ nucleotide sequence \\
\hline $\mathrm{Cl}$.rev & CTTCAACGCTAACTTTGAG \\
\hline rasP.PO & GCTCTTCAAGGCGAACAGG \\
\hline rasP.P1 & CGCCTCATCATTACGGCATC \\
\hline rasP.P2 & $\begin{array}{l}\text { CGACCTGCAGGCATGCAAGCTACCACCTTATGTGAGTA } \\
\text { TTGAATTGAC }\end{array}$ \\
\hline rasP.P3 & $\begin{array}{l}\text { CGAGCTCGAATTCACTGGCCGTCGGGATACGTCAATTCA } \\
\text { ATACTCACATAAGGTGGTACGAAAAGTAAATCAATCAG } \\
\text { AGGTGC }\end{array}$ \\
\hline rasP.P4 & GATCGTACGGCGCAACG \\
\hline tepA.PO & CGCACGGGCACGATG \\
\hline tepA.P1 & CTGTCCGTTCCAGTGTACGG \\
\hline tepA.P2 & $\begin{array}{l}\text { CGACCTGCAGGCATGCAAGCTCTCGCTTTCATC- } \\
\text { CTTTCCG }\end{array}$ \\
\hline tepA.P3 & $\begin{array}{l}\text { CGAGCTCGAATTCACTGGCCGTCGCAAAGAGAAACTC } \\
\text { GGAAAGGATGAAAGCGAGTTCTTTATACCGTGATGCC } \\
\text { TCAG }\end{array}$ \\
\hline tepA.P4 & GGTCTGTCATTCAATTTAGACTCCAG \\
\hline pHT315CPEC.fw & CTATGAGTCGCTTTTTTAAATTTGGAAAGTTAC \\
\hline pHT315CPEC.rev & CACTGTTTTTAGTCTGTTTCAAAACAGTAG \\
\hline kanaCPEC.fw & $\begin{array}{l}\text { CTACTGTTTTGAAACAGACTAAAAACAGTGGCTCCGTCG } \\
\text { ATACTATGTTATACG }\end{array}$ \\
\hline kanaCPEC.rev & $\begin{array}{l}\text { TAACTTTCCAAATTTAAAAAAGCGACTCATAGGCTTTTTA } \\
\text { GACATCTAAATCTAGGTAC }\end{array}$ \\
\hline pHT315rasP.fw & $\begin{array}{l}\text { GTGAGTATTGAATTGACGTATCCCCGCCCGGGTACCGAG } \\
\text { CTCTTAATTG }\end{array}$ \\
\hline pHT315rasP.rev & $\begin{array}{l}\text { GCGAAGAAATGAGACAAAGCTTGACGGCTTGGCGTAAT } \\
\text { CATGGTCATAGC TG }\end{array}$ \\
\hline rasP.fw & CGGGGATACGTCAATTCAATACTCAC \\
\hline rasP.rev & CGTCAAGCTTTGTCTCATTTCTTCGC \\
\hline
\end{tabular}

chloramphenicol in Ultra Yield Flasks ${ }^{\mathrm{TM}}$ (Thomson Instrument Company) and incubated for approximately $16 \mathrm{~h}$ at $37{ }^{\circ} \mathrm{C}, 280 \mathrm{rpm}$ in a Multitron orbital shaker (Infors) at high humidity. After measuring and correcting for the optical density at $600 \mathrm{~nm}\left(\mathrm{OD}_{600}\right)$, equal amounts of cells were separated from the culture medium by centrifugation. For the analysis of extracellular proteins, proteins in the culture medium were precipitated with trichloroacetic acid (TCA; 10\% w/v final concentration), dissolved in LDS buffer (Life Technologies) and heated for $10 \mathrm{~min}$ at $95{ }^{\circ} \mathrm{C}$. Next, proteins were separated by LDS-PAGE on $10 \%$ NuPage gels (Life Technologies). Gels were stained with SimplyBlue ${ }^{\mathrm{TM}}$ SafeStain (Life Technologies). Gel images were quantified with the ImageJ software (http:// imagej.nih.gov/ij/).

\section{Pulse-chase protein labeling experiments}

Pulse-chase labeling of B. subtilis proteins was performed using Easy tag $\left[{ }^{35} \mathrm{~S}\right]$-methionine (PerkinElmer Inc.). Immunoprecipitation and LDS-PAGE were performed as described previously [39] using the following adaptations. Cells were grown for $16 \mathrm{~h}$ in MBU with $2.5 \mu \mathrm{g} /$ $\mathrm{ml}$ chloramphenicol as described before and diluted $1 \mathrm{~h}$ prior to the actual labeling to $\mathrm{OD}_{600} \sim 0.7$ in fresh $\mathrm{MBU}$ with $2.5 \mu \mathrm{g} / \mathrm{ml}$ chloramphenicol. Labeling was performed with $25 \mu \mathrm{Ci}\left[{ }^{35} \mathrm{~S}\right]$-methionine for $30 \mathrm{~s}$ before adding an excess amount of unlabeled methionine (chase; $0.6 \mathrm{mg} /$ $\mathrm{ml}$ final concentration). Samples were collected at several time points, followed by direct precipitation of the proteins with $10 \%$ TCA (w/v) on ice. Precipitates were re-suspended in lysis buffer $(10 \mathrm{mM}$ Tris $\mathrm{pH} 8,25 \mathrm{mM}$ $\mathrm{MgCl}_{2}, 200 \mathrm{mM} \mathrm{NaCl}$ and $5 \mathrm{mg} / \mathrm{ml}$ lysozyme). After $10-15 \mathrm{~min}$ incubation at $37^{\circ} \mathrm{C}$, lysis was achieved by adding $1 \%(\mathrm{w} / \mathrm{v}) \mathrm{SDS}$ and heating for $10 \mathrm{~min}$ at $100^{\circ} \mathrm{C}$. Specific polyclonal antibodies against AmyE or AmyL were used for immunoprecipitation of the respective labeled proteins in STD-Tris buffer $(10 \mathrm{mM}$ Tris $\mathrm{pH}$ 8.2, $0.9 \%$ $(\mathrm{w} / \mathrm{v}) \mathrm{NaCl}, 1.0 \%(\mathrm{v} / \mathrm{v})$ triton $\mathrm{X}-100,0.5 \%(\mathrm{w} / \mathrm{v})$ sodium deoxycholate) with the help of Protein A affinity medium (Mabselect Sule, GE Healthcare Life Sciences).

Because of the high proteolytic activity of BPN', which also degrades antibodies, the immunoprecipitation of $\mathrm{BPN}^{\prime}$ was performed in the presence of a specific serine protease inhibitor (4 mM, Pefablock SC, Roche). Due to aspecific binding of the $\mathrm{BPN}^{\prime}$ antibodies to unidentified cellular proteins of $B$. subtilis, the immunoprecipitation of $\mathrm{BPN}^{\prime}$ was only performed to assay secreted $\mathrm{BPN}^{\prime}$ in TCA-precipitated culture medium samples. Labeled proteins were separated by LDS-PAGE using $10 \%$ NuPage gels (Life Technologies) and visualized using a Cyclon Plus Phosphor Imager (Perkin Elmer). Quantification of the obtained data was achieved by making use of the ImageJ software.

For pulse-chase labeling studies on the complementation of the $\triangle$ rasP mutation, cells containing pHTK315ras $P$ or control cells containing the empty vector pHTK315 were pre-cultured for $20 \mathrm{~h}$ in MBU with $2.5 \mu \mathrm{g} / \mathrm{ml}$ chloramphenicol, because these cells grow slightly slower than cells without such plasmids. One hour prior to labeling with $\left[{ }^{35} \mathrm{~S}\right]$-methionine, the cells were diluted to an $\mathrm{OD}_{600}$ of $\sim 0.7$ in fresh $\mathrm{MBU}$ with $2.5 \mu \mathrm{g} / \mathrm{ml}$ chloramphenicol containing $25 \mu \mathrm{M}$ isopropyl $\beta$-D-1-thiogalactopyranoside (IPTG) necessary for the induction of the $\mathrm{P}_{\text {spac }}$ promoter. The pulse-chase protein labeling was performed as described above.

\section{Assays for Properase or AmyAc production}

To analyze Properase secretion by cells overexpressing $\operatorname{ras} P$ or wt control cells, the respective strains were pre-cultured for $5 \mathrm{~h}$ in LB at $37^{\circ} \mathrm{C}$. From these precultures $1.5 \mathrm{OD}$ units were used to inoculate $25 \mathrm{ml}$ of MBU medium in Ultra Yield Flasks ${ }^{\mathrm{TM}}$, and culturing was continued at $37{ }^{\circ} \mathrm{C}$ ( $250 \mathrm{rpm}, 70 \%$ humidity). Samples were withdrawn from the cultures at 18, 25, 41, 48 and $65 \mathrm{~h}$ of growth for $\mathrm{OD}_{600}$ readings and protease activity 
measurements. $\mathrm{OD}_{600}$ was determined using a SpectraMax spectrophotometer (Molecular Devices, Downington, PA, USA). Protease activity in the samples was determined by incubating sample aliquots with the synthetic substrate $\mathrm{N}$-Succinyl-Ala-Ala-Pro-Phe $p$-nitroanilide (Sigma Chemical Co) and absorbance readings at $405 \mathrm{~nm}$ using a SpectraMax spectrophotometer, as described previously in WO 2010/144283.

To test the effect of rasP overexpression on the production of AmyAc, four colonies from the rasP overexpressing strain or the wt control strain were used to inoculate LB with $25 \mu \mathrm{g} / \mathrm{ml}$ chloramphenicol and the resulting pre-cultures were grown for $4 \mathrm{~h}$ at $37^{\circ} \mathrm{C}$. Next, $0.075 \mathrm{OD}$ units from a pre-culture were used to inoculate $2 \mathrm{ml}$ of medium (5SM12 or MBU) in 24 deep well microtiter plates and cultures were grown for $48 \mathrm{~h}$ at $37^{\circ} \mathrm{C}$ under vigorous shaking. Samples were withdrawn at 18, 25, 41 and $48 \mathrm{~h}$ of culturing for $\mathrm{OD}_{600}$ readings and amylase activity measurements. Amylase activity in whole-broth samples was assayed with the Ceralpha HR kit (Megazyme, Wicklow, Ireland) and absorbance readings at $400 \mathrm{~nm}$ according to the manufacturer's instructions.

\section{Results and discussion}

As a first approach to assess the possible function of RasP in protein secretion under fermentation-mimicking conditions, the rasP gene was deleted from the $B$. subtilis genome and the secretion of three representative model proteins was assessed in the resulting $\triangle$ ras $P$ strain. Specifically, the secreted model proteins were the $\alpha$-amylase AmyE from B. subtilis, the $\alpha$-amylase AmyL from Bacillus licheniformis and the serine protease $\mathrm{BPN}^{\prime}$ from $B$. amyloliquefaciens. The respective genes were expressed to high levels using the aprE promoter, which is a preferred promoter for enzyme production at industrial scale [40]. As shown in Fig. 1, $\Delta$ ras $P$ cells grown to stationary phase in about $16-20 \mathrm{~h}$ of culturing secreted less AmyE, AmyL or and BPN' than wild-type cells. This was clearly not the case for control cells lacking the tep $A$ gene, which encodes an unrelated cytoplasmic protease [41]. Furthermore, the rates of AmyE and AmyL precursor processing as determined by pulse-chase labeling with $\left.{ }^{35} \mathrm{~S}\right]$-methionine after $16 \mathrm{~h}$ of growth were substantially reduced in $\triangle$ ras $P$ cells compared to wild-type cells (Fig. 2a). In case of $\mathrm{BPN}^{\prime}$ we were unable to detect cell-associated precursor forms of this protein but, nonetheless, we showed that the rate of appearance of the mature $\left.{ }^{35} \mathrm{~S}\right]$-methionine-labeled $\mathrm{BPN}^{\prime}$ in the growth medium was strongly slowed down in cells lacking ras $P$ (Fig. 2b). Together, these findings clearly demonstrate that RasP is needed for efficient processing and secretion of mature AmyE, AmyL and BPN'. As illustrated with AmyE, the wild-type rate of precursor processing

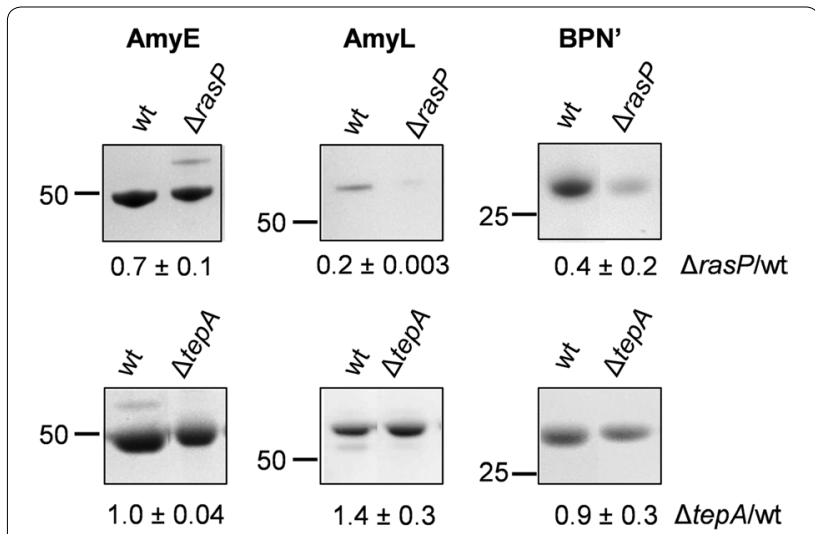

Fig. 1 Reduced secretion levels of AmyE, AmyL and BPN' in ras $P$ mutant cells. $\triangle$ ras $P$ mutant cells and wild-type (wt) or $\triangle$ tepA mutant control cells expressing AmyE, AmyL or BPN' were grown for $16 \mathrm{~h}$ in MBU medium. Next, cells and growth media were separated by centrifugation. Proteins in growth medium fractions were precipitated with TCA and analyzed by LDS-PAGE. Protein bands were visualized with the SimplyBlue SafeStain. Molecular weights of marker proteins are indicated (in $\mathrm{kDa}$ ) on the left side of each gel segment. Secreted amounts of AmyE, AmyL and BPN' in the growth medium fractions from three independent cultures were assessed by ImageJ analysis of the gels, and the ratios of each of these proteins in the medium fractions of the $\triangle$ ras $P$ or $\triangle t e p A$ strains relative to the wt strain are indicated below each gel segment together with the standard deviation

and secretion of the mature protein were restored when ras $P$ was expressed from a plasmid in the $\triangle$ ras $P$ cells (Figs. 3,4 ). This shows that the $\triangle$ ras $P$ mutation can be complemented with rasP expressed in trans. Of note, the wild-type cells grew to higher optical densities at $600 \mathrm{~nm}$ $\left(\mathrm{OD}_{600} \sim 25\right)$ than the $\Delta$ rasP cells $\left(\mathrm{OD}_{600} \sim 15\right)$, but this effect was corrected for in the loading of gels shown in Figs. 1 and 3, and in the pulse-chase labelling experiments in Figs. 2 and 4 comparable amounts of cells were used.

Because the removal of RasP had significant influence on the processing and secretion of AmyL, AmyE and $\mathrm{BPN}^{\prime}$, we wanted to know whether ras $P$ overexpression could be beneficial for protein secretion in $B$. subtilis. Notably, in 'wild-type' B. subtilis the secretion of AmyL, AmyE and BPN' is already very efficient. Moreover, these enzymes are produced really well in other industrial Bacillus species, which gives the optimization of their production in B. subtilis a lower commercial impact. Therefore, we focused our attention on two other enzymes, namely a protease ('Properase') from B. clausii and AmyAc from P. curdlanolyticus, which are both commercially valuable but hard to produce. Especially the large-scale production of enzymes of the AmyAc family is very challenging in Bacillus species. To overexpress rasP, this gene was placed under control of the very strong spoVG promoter (PspoVG). Importantly, the PspoVG 

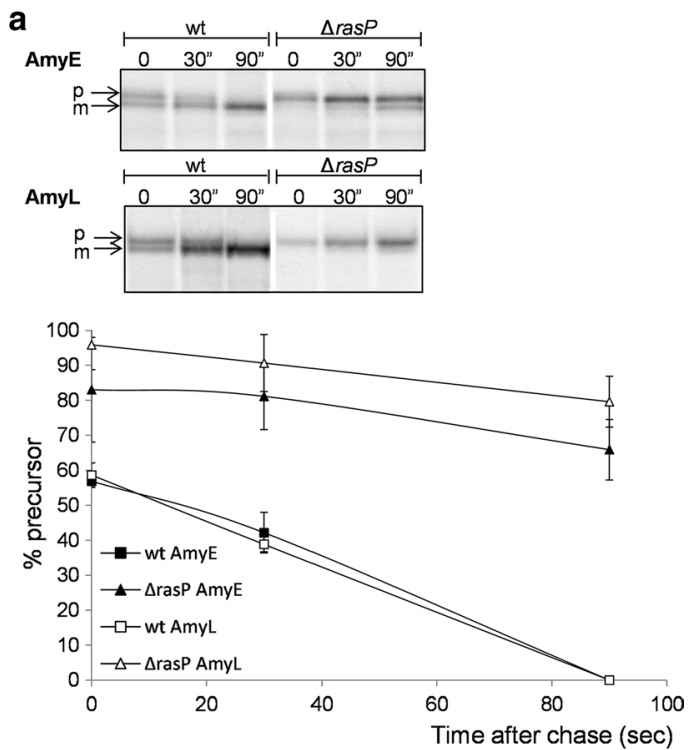

b

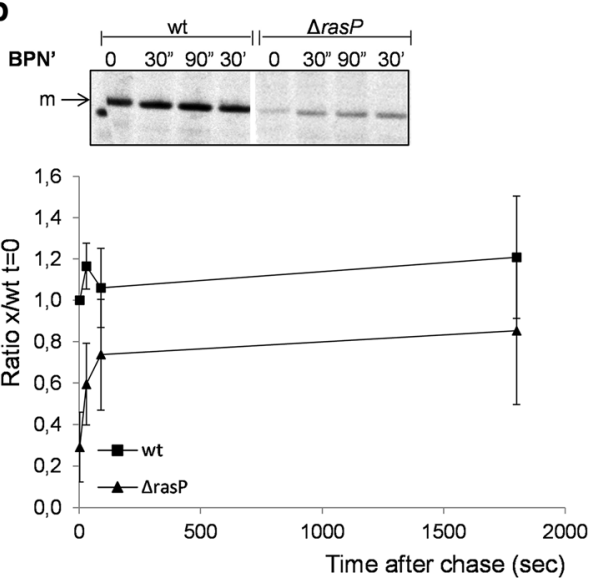

Fig. 2 Reduced rates of AmyE, AmyL and BPN'secretion in ras $P$ mutant cells. a Processing of the precursor proteins of AmyE or AmyL by signal peptidase was analyzed by pulse-chase protein labeling with $\left.{ }^{35} \mathrm{~S}\right]$-methionine, immunoprecipitation of AmyE or AmyL from culture samples with specific antibodies, LDS-PAGE and phosphorimaging as described in "Methods". The positions of precursor (p) and mature (m) forms of AmyE and AmyL are indicated. Data from three independent experiments were analyzed with ImageJ to assess the kinetics of precursor processing, and the results are plotted below the autoradiographs. The plot shows the relative amounts (\%) of the precursor forms of AmyE (black symbols) or AmyL (white symbols) in the $\triangle$ ras $P$ (triangle) or wt (square) strains at different time points after the chase with nonradioactive methionine $(t=0)$. Error bars show the standard deviation. b Secretion of BPN' was analyzed by pulse-chase labeling with $\left[{ }^{35} \mathrm{~S}\right]$-methionine, immunoprecipitation from growth medium fractions devoid of cells with specific antibodies, LDS-PAGE and phosphorimaging as described in "Methods". The position of mature BPN' is indicated $(\mathrm{m})$. Data from three independent experiments were analyzed with ImageJ to determine the kinetics BPN'appearance in the growth medium, and the results are plotted below the autoradiographs. The plot shows the average of the calculated ratio of secreted BPN' in the $\triangle$ rasP (triangle) or wt (square) strains relative to the amount of BPN' secreted immediately after the chase with non-radioactive methionine $(\mathrm{t}=0)$ in the wt strain. Error bars indicate the standard deviation

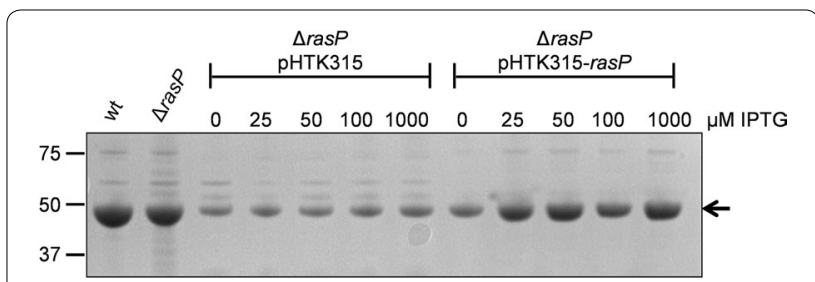

Fig. 3 IPTG-dependent complementation of the $\triangle$ ras $P$ mutation in AmyE-producing cells containing pHTK315-rasP. $\triangle$ ras $P$ mutant bacteria overproducing AmyE and carrying either pHTK315-ras $P$ or the empty vector pHTK315 were grown for $16 \mathrm{~h}$ in MBU with $2.5 \mathrm{\mu g} / \mathrm{ml}$ chloramphenicol. Next ras $P$ expression in cells containing pHTK315-ras $P$, where ras $P$ is transcribed from the IPTG-dependent $\mathrm{P}_{\text {spac }}$ promoter, was induced for $4 \mathrm{~h}$ by the addition of IPTG to different end concentrations as indicated. $\triangle$ ras $P$ mutant bacteria carrying the empty vector PHTK315 were also treated with IPTG as a negative control. Proteins in the growth medium were precipitated with TCA and separated by LDS-PAGE. Protein bands were visualized with the SimplyBlue SafeStain. The AmyE band is indicated with an arrow, and the molecular weights of marker proteins are indicated on the left of the gel (in $\mathrm{kDa}$ )

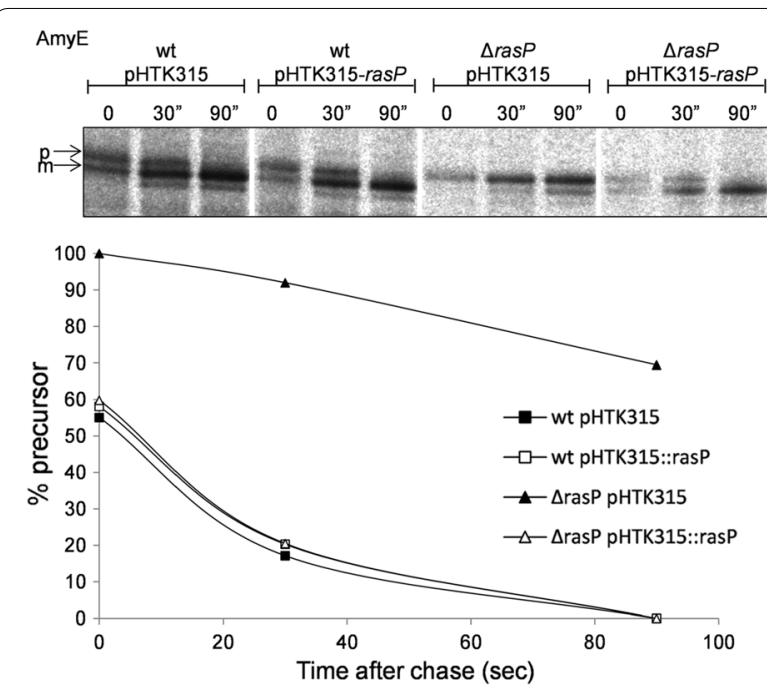

Fig. 4 Complementation of pre-AmyE processing in $\triangle$ ras $P$ mutant cells. Processing of pre-AmyE (p) to mature AmyE (m) was analyzed by pulse-chase protein labeling with $\left.{ }^{35} \mathrm{~S}\right]$-methionine in IPTGinduced $\triangle$ ras $P$ mutant or wt cells containing either PHTK315-ras $P$ or the empty vector $\mathrm{PHTK} 315$. Pre-AmyE and mature AmyE were immunoprecipitated with specific antibodies, separated by LDSPAGE, and visualized by a phosporimaging. Data from two independent experiments were analyzed with ImageJ to assess the kinetics of pre-AmyE processing to the mature form, and the results are plotted below the autoradiographs. Specifically, the plot shows the relative amounts (\%) of the precursor form of AmyE in $\triangle$ ras P mutant (triangle) or wt (square) cells carrying pHTK315-rasP (white symbols) or pHTK315 (black symbo/s) at different time points after the chase with non-radioactive methionine $(t=0)$

promoter is a constitutive promoter and its strength is comparable to that of the promoter of aprE, which was used to express the secreted proteins employed in 
this study (data not shown). Next, the capability of the resulting strain to secrete the highly active Properase, which is even capable of degrading prions, was tested. A potential problem caused by high-level Properase production is a negative effect on the viability of $B$. subtilis. As shown in Fig. 5a, PspoVG-driven expression of rasP enhanced both cell viability and the secretion of Properase in the production phase when cells were grown in MBU medium. Of note, high-level rasP expression led to an increase in Properase production of about threefold. To further obtain proof-of-principle that PspoVG-driven ras $P$ expression may be beneficial for secretory protein
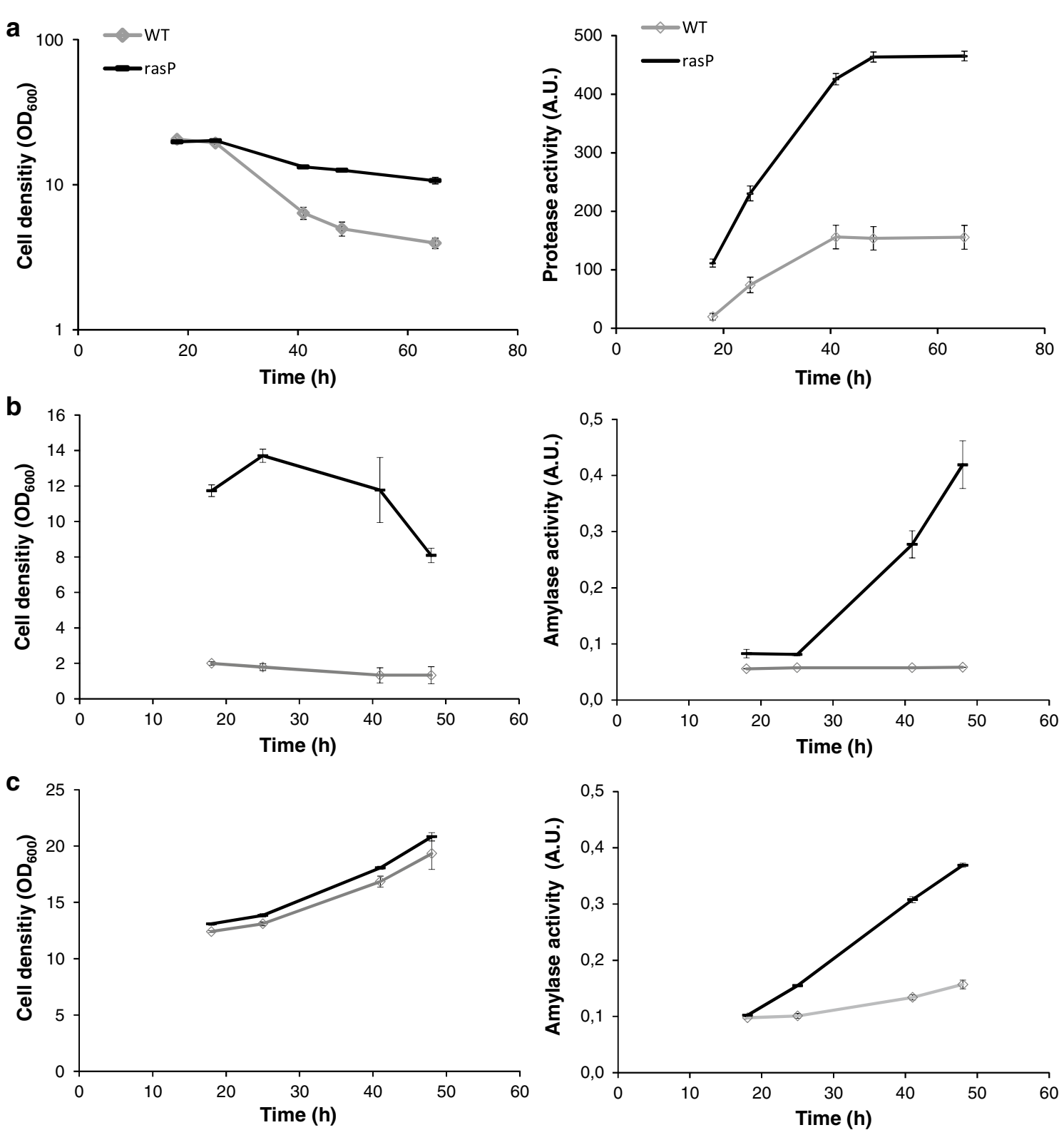

Fig. 5 Improved production of Properase and AmyAc upon overexpression of rasP. a Growth (left panel) and extracellular Properase activity (right panel) of cells cultured in MBU medium. Measurements on cells that overexpress rasP from the strong PspoVG promoter are indicated with black lines and measurements on wt cells are indicated with grey lines. b Growth (left panel) and extracellular AmyAc activity (right panel) of cells that overexpress rasP from the PspoVG promoter (black lines) or wt cells (grey lines) cultured in MBU medium. c Growth (left panel) and extracellular AmyAc activity (right panel) of cells that overexpress rasP from the PspoVG promoter (black lines) or wt cells (grey lines) cultured in 5SM12 medium. All plots in a-c show average values from three independent experiments, and the error bars represent the standard deviations of the respective measurements 
production, we investigated the effect on production of a bacterial $\alpha$-amylase belonging to the AmyAc family. Similar to Properase, the expression of the AmyAc enzyme had a negative impact on growth in MBU medium and, in this case, both growth and amylase production remained relatively low unless rasP was overexpressed (Fig. 5b). In fact, AmyAc production by cells grown in MBU was up to tenfold increased upon rasP overexpression. Interestingly, expression of the AmyAc enzyme does not impact on growth in 5SM12 medium, which allowed us to distinguish between growth effects and effects of rasP overexpression on production of the secreted AmyAc enzyme. As shown in Fig. 5c, the yield of this enzyme in the 5SM12 growth medium was about 2.5-fold increased, which implies that the improved productivity was mostly directly related to rasP overexpression rather than an enhanced cell density of the culture. The main difference between the $5 \mathrm{SM} 12$ and MBU media is that the $5 \mathrm{SM} 12$ medium contains soytone and 3.4-fold more maltodextrin. This suggests that AmyAc production may have a negative impact on nutrient acquisition by cells grown in $\mathrm{MBU}$, which can be bypassed either by rasP overexpression or the provision of soytone and/or additional maltodextrin. Altogether, our results imply that rasP overexpression gives significant benefits for producing secretory proteins commercially.

\section{Conclusions}

In conclusion, our present study shows that the S2P intramembrane protease RasP sets the limit to efficient extracellular production of two proteins in B. subtilis, namely Properase and an AmyAc type amylase. These proteins are difficult to produce, which is partly due to effects on cell growth and/or viability in late stages of the fermentation process. Enhanced expression of rasP can overcome these negative effects, and seems even capable of boosting the secretion of the AmyAc type amylase up to tenfold. Our present findings are unprecedented, giving the first proof-of-principle that overexpression of a protease that cleaves within the plane of the cytoplasmic membrane of a bacterium can lead to improved protein production. The precise mechanism by which RasP exerts this effect in Bacillus is not yet known but, based on knowledge from other studies on S2P proteases, we envisage at least three possible scenarios. Firstly, RasP may facilitate the removal of cleaved signal peptides from the membrane [25], secondly, RasP may clear the membrane of mislocalized secretory precursor proteins that may interfere with essential membrane processes [20], or thirdly, overproduced RasP may modulate expression of $\sigma^{\mathrm{w}}$-dependent genes that somehow influence productivity [26]. In these three scenarios, rasP overexpression could increase the fitness of the producing cells through the prevention of membrane and cell envelope perturbations. This would then lead to enhanced growth and productivity. A fourth possible explanation would be that RasP activity precludes potentially inhibitory effects of accumulating signal peptides on the SecA preprotein translocation motor [42] and/or on signal peptidases that convert translocated precursors of secretory proteins to the mature form [43]. Of course, combinations of these four scenarios are also conceivable. Irrespective of the precise mechanisms, we conclude that RasP can be applied to boost protein secretion in Bacillus, and that the overexpression of this and other S2P proteases represents a promising avenue for future cell factory engineering.

\section{Abbreviations \\ GRAS: Generally Recognized As Safe; IPTG: isopropyl $\beta$-D-1- \\ thiogalactopyranoside; LDS: lithium dodecyl sulphate; $\mathrm{OD}_{600}$ : optical density at $600 \mathrm{~nm}$; PAGE: polyacrylamide gel electrophoresis; PCR: polymerase chain reaction; QPS: Qualified Presumption of Safety; S2P: site-2 protease; TCA: trichloroacetic acid. \\ Authors' contributions \\ $J N, C B, B S$ and $J M v D$ conceived the study and analyzed the data; JN, CB, VJG and JMvD performed the experiments; and JN, CB and JMvD wrote the paper. All authors read and approved the final manuscript. \\ Author details \\ ${ }^{1}$ Department of Medical Microbiology, University of Groningen, University Medical Center Groningen, Hanzeplein 1, P.O. Box 30001, 9700 RB Groningen, The Netherlands. ${ }^{2}$ DuPont Industrial Biosciences, 925 Page Mill Road, Palo Alto, CA 94304, USA. ${ }^{3}$ Present Address: Department of Bioengineering, Centre for Synthetic Biology, Imperial College London, London SW7 2AZ, UK.}

\section{Acknowledgements}

Not applicable.

\section{Competing interests}

$J N, V J G$ and JMVD declare no competing financial interests. CB and BS are employees of DuPont Industrial Biosciences.

Availability of data and materials

All data generated or analyzed during this study are included in this published article.

\section{Consent for publication}

The present manuscript has been seen and approved by all authors. They agree with its content and submission to Microbial Cell Factories.

\section{Funding}

This work was supported by funding from Genencor/Dupont.

\section{Publisher's Note}

Springer Nature remains neutral with regard to jurisdictional claims in published maps and institutional affiliations.

Received: 30 December 2016 Accepted: 31 March 2017

Published online: 04 April 2017

\section{References}

1. Van Dijl JM, Hecker M. Bacillus subtilis: from soil bacterium to super-secreting cell factory. Microb Cell Fact. 2013;12(1):3. 
2. Sarvas M, Harwood CR, Bron S, Van Dijl JM. Post-translocational folding of secretory proteins in Gram-positive bacteria. Biochim Biophys Acta. 2004;1694:311-27.

3. Palva I. Molecular cloning of alpha-amylase gene from Bacillus amyloliquefaciens and its expression in B. subtilis. Gene. 1982;19(1):81-7.

4. Krishnappa L, Dreisbach A, Otto A, Goosens VJ, Cranenburgh R, Harwood CR, Becher D, Van Dijl JM. Extracytoplasmic proteases determining the cleavage and release of secreted proteins, lipoproteins, and membrane proteins in Bacillus subtilis. J Proteome Res. 2013:12:4101-10.

5. Westers L, Westers H, Quax WJ. Bacillus subtilis as cell factory for pharmaceutical proteins: a biotechnological approach to optimize the host organism. Biochim Biophys Acta. 2004;1694:299-310.

6. Olempska-Beer ZS, Merker RI, Ditto MD, DiNovi MJ. Food-processing enzymes from recombinant microorganisms - a review. Regul Toxicol Pharmacol. 2006:45(2):144-58.

7. Earl AM, Losick R, Kolter R. Ecology and genomics of Bacillus subtilis. Trends Microbiol. 2008;16(6):269-75.

8. Brockmeier U, Caspers M, Freudl R, Jockwer A, Noll T, Eggert T. Systematic screening of all signal peptides from Bacillus subtilis: a powerful strategy in optimizing heterologous protein secretion in Gram-positive bacteria. J Mol Biol. 2006;362(3):393-402

9. Caspers M, Brockmeier U, Degering C, Eggert T, Freudl R. Improvement of Sec-dependent secretion of a heterologous model protein in Bacillus subtilis by saturation mutagenesis of the $\mathrm{N}$-domain of the AmyE signal peptide. Appl Microbiol Biotechnol. 2010;86(6):1877-85.

10. Pohl S, Bhavsar G, Hulme J, Bloor AE, Misirli G, Leckenby MW, Radford DS, Smith W, Wipat A, Williamson ED, Harwood CR, Cranenburgh RM. Proteomic analysis of Bacillus subtilis strains engineered for improved production of heterologous proteins. Proteomics. 2013;13(22):3298-308.

11. Luo Z, Gao Q, Li X, Bao J. Cloning of LicB from Clostridium thermocellum and its efficient secretive expression of thermostable beta-1,3-1,4-glucanase. Appl Biochem Biotechnol. 2014;173(2):562-70.

12. Wu XC, Ng SC, Near RI, Wong SL. Efficient production of a functional single-chain antidigoxin antibody via an engineered Bacillus subtilis expression-secretion system. Biotechnology (N Y). 1993;11(1):71-6.

13. Westers L, Dijkstra DS, Westers H, van Dijl JM, Quax WJ. Secretion of functional human interleukin-3 from Bacillus subtilis. J Biotechnol. 2006;123(2):211-24

14. Bolhuis A, Sorokin A, Azevedo V, Ehrlich SD, Braun PG, De Jong A, Venema G, Bron S, Van Dijl JM. Bacillus subtilis can modulate its capacity and specificity for protein secretion through temporally controlled expression of the sipS gene for signal peptidase I. Mol Microbiol. 1996;22(4):605-18

15. Kontinen VP, Sarvas M. The PrsA lipoprotein is essential for protein secretion in Bacillus subtilis and sets a limit for high-level secretion. Mol Microbiol. 1993;8(4):727-37.

16. Kouwen TR, van der Goot A, Dorenbos R, Winter T, Antelmann H, Plaisier MC, Quax WJ, van Dijl JM, Dubois JY. Thiol-disulphide oxidoreductase modules in the low-GC Gram-positive bacteria. Mol Microbiol. 2007:64(4):984-99.

17. Chen J, Fu G, Gai Y, Zheng P, Zhang D, Wen J. Combinatorial Sec pathway analysis for improved heterologous protein secretion in Bacillus subtilis: identification of bottlenecks by systematic gene overexpression. Microb Cell Fact. 2015;14:92. doi:10.1186/s12934-015-0282-9.

18. Bramkamp M, Weston L, Daniel RA, Errington J. Regulated intramembrane proteolysis of FtsL protein and the control of cell division in Bacillus subtilis. Mol Microbiol. 2006;62(2):580-91.

19. Zweers JC, Wiegert T, van Dijl JM. Stress-responsive systems set specific limits to the overproduction of membrane proteins in Bacillus subtilis. Appl Environ Microbiol. 2009;75(23):7356-64.

20. Heinrich J, Hein K, Wiegert T. Two proteolytic modules are involved in regulated intramembrane proteolysis of Bacillus subtilis RsiW. Mol Microbiol. 2009;74(6):1412-26.

21. Heinrich J, Lundén T, Kontinen VP, Wiegert T. The Bacillus subtilis ABC transporter EcsAB influences intramembrane proteolysis through RasP. Microbiology. 2008;154:1989-97.

22. Yuan J, Zweers JC, van Dij JM, Dalbey RE. Protein transport across and into cell membranes in bacteria and archaea. Cell Mol Life Sci. 2010;67(2):179-99.

23. Dalbey RE, Wang P, van Dijl JM. Membrane proteases in the bacterial protein secretion and quality control pathway. Microbiol Mol Biol Rev. 2012:76(2):311-30.
24. Akiyama Y, Kanehara K, Ito K. RseP (YaeL), an Escherichia coli RIP protease, cleaves transmembrane sequences. EMBO J. 2004;23:4434-42.

25. Saito A, Hizukuri Y, Matsuo E, Chiba S, Mori H, Nishimura O, Ito K, Akiyama Y. Post-liberation cleavage of signal peptides is catalyzed by the site-2 protease (S2P) in bacteria. Proc Natl Acad Sci USA. 2011;108(33):13740-5.

26. Zweers JC, Nicolas P, Wiegert T, Van Dijl JM, Denham EL. Definition of the $\sigma(W)$ regulon of Bacillus subtilis in the absence of stress. PLoS ONE. 2012;7(11):e48471.

27. Helmann JD. Bacillus subtilis extracytoplasmic function (ECF) sigma factors and defense of the cell envelope. Curr Opin Microbiol. 2016:30:122-32.

28. Vogtentanz G, Collier KD, Bodo M, Chang JH, Day AG, Estell DA, Falcon BC, Ganshaw G, Jarnagin AS, Kellis JT Jr, Kolkman MA, Lai CS, Meneses R, Miller JV, de Nobel H, Power S, Weyler W, Wong DL, Schmidt BF. A Bacillus subtilis fusion protein system to produce soybean Bowman-Birk protease inhibitor. Protein Expr Purif. 2007;55(1):40-52.

29. Fabret C, Ehrlich SD, Noirot P. A new mutation delivery system for genome-scale approaches in Bacillus subtilis. Mol Microbiol. 2002;46(1):25-36

30. Yang M, Galizzi A, Henner D. Nucleotide sequence of the amylase gene from Bacillus subtilis. Nucleic Acids Res. 1983;1 1(2):237-49.

31. Yuuki T, Nomura T, Tezuka H, Tsuboi A, Yamagata H, Tsukagoshi N, Udaka $\mathrm{S}$. Complete nucleotide sequence of a gene coding for heat- and $\mathrm{pH}-$ stable alpha-amylase of Bacillus licheniformis: comparison of the amino acid sequences of three bacterial liquefying alpha-amylases deduced from the DNA sequences. J Biochem. 1985;98(5):1147-56.

32. Wells JA, Ferrari E, Henner DJ, Estell DA, Chen EY. Cloning, sequencing, and secretion of Bacillus amyloliquefaciens subtilisin in Bacillus subtilis. Nucleic Acids Res. 1983;11(22):7911-25.

33. Wells JA, Cunningham BC, Graycar TP, Estell DA. Recruitment of substratespecificity properties from one enzyme into a related one by protein engineering. Proc Natl Acad Sci USA. 1987;84(15):5167-71.

34. Valle F, Ferrari E. Subtilisin: a redundantly temporally regulated gene. In: Smith I, Slepecky AR, Selow P, editors. Regulation of prokaryotic development. Washington: American Society for Microbiology; 1989. p. 131-46.

35. Perego M. Integrational vectors for genetic manipulation in Bacillus subtilis. In: Sonenshein AL, Hoch JA, Losick R, editors. Bacillus subtilis and other Gram-positive bacteria: biochemistry, physiology, and molecular genetics. Washington: American Society for Microbiology; 1993. p. 615-24.

36. Fukushima T, Furihata I, Emmins R, Daniel RA, Hoch JA, Szurmant H. A role for the essential YycG sensor histidine kinase in sensing cell division. Mol Microbiol. 2011;79(2):503-22.

37. Quan J, Tian J. Circular polymerase extension cloning of complex gene libraries and pathways. PLoS ONE. 2009;4(7):e6441.

38. Meijer WJ, de Jong A, Bea G, Wisman A, Tjalsma H, Venema G, Bron S, van Dij JM. The endogenous Bacillus subtilis (natto) plasmids pTA1015 and pTA1040 contain signal peptidase-encoding genes: identification of a new structural module on cryptic plasmids. Mol Microbiol. 1995;17(4):621-31.

39. Van Dijl JM, De Jong A, Smith H, Bron S, Venema G. Non-functional expression of Escherichia coli signal peptidase I in Bacillus subtilis. J Gen Microbiol. 1991;137:2073-83.

40. Ferrari E, Valle F. Mutant aprE promoter. Genencor. 2000; EP1244794 B1.

41. Bolhuis A, Matzen A, Hyyryläinen HL, Kontinen VP, Meima R, Chapuis J, Venema G, Van Dijl JM. Singal peptide peptidase- and ClpP-like proteins of Bacillus subtilis required for efficient translocation and processing of secretory proteins. J Biol Chem. 1999;274(35):24585-92.

42. Cunningham K, Wickner W. Specific recognition of the leader region of precursor proteins is required for the activation of translocation ATPase of Escherichia coli. Proc Natl Acad Sci USA. 1989;86:8630-4.

43. Wickner W, Moore K, Dibb N, Geissert D, Rice M. Inhibition of purified Escherichia coli leader peptidase by the leader (signal) peptide of bacteriophage M13 procoat. J Bacteriol. 1987;169:3821-2.

44. Worner K, Szurmant H, Chiang C, Hoch JA. Phosphorylation and functional analysis of the sporulation initiation factor SpoOA from Clostridium botulinum. Mol Microbiol. 2006:59(3):1000-12. 